\title{
Understanding the pathophysiology of migraine pain
}

\author{
Rose Fluss*, Andrew J Kobets and David J Altschul \\ Leo M. Davidoff Department of Neurological Surgery, Montefiore Medical Center/Albert Einstein College of Medicine, 111 East 210th Street, The Bronx, New \\ York, USA
}

\begin{abstract}
Abbreviations: MRA: Magnetic Resonance Angiography; MMA: Middle Meningeal Artery; ECA: External Carotid Artery; DSA: Digital Subtraction Angiography
\end{abstract}

Migraine disorder is a highly prevalent disease affecting 28 million people worldwide and have been cited to have a global economic burden placed at over 20 billion dollars [1,2]. Although not traditionally viewed as a systemic illness, the health-related impact of migraines has been compared with congestive heart failure, hypertension, and diabetes [3]. Definitive treatment of migraines as well as the pathophysiology of migraines remain uncertain. The trigeminovascular system, which includes the sensory fibers of the external and internal carotid arteries have been long implicated in the pain and cutaneous allodynia experienced by migraine patients $[4,5]$. Wolff was the first to posit that migraines were caused by carotid artery vasodilation and demonstrated that pulse amplitudes of the carotid artery were directly correlated to migraine symptomatology. Conversely, associated auras were speculated to stem from changes in the internal carotid artery [6].

Further evidence that the aetiology of migraine headaches is not a purely an intracranial process resulted from reported induction of migraines in patients receiving nitroglycerine injections over placebo [7]. Administration of nitroglycerine, a potent dilator of blood vessels, prior to magnetic resonance angiography (MRA) showed the greatest increase in vessel diameter in the extracranial vasculature i.e. middle meningeal artery (MMA) and the external carotid artery, ECA [7]. More work has built on these findings during spontaneous and provoked migraines, and the prevailing theory now implicates dilation of the external carotid artery with symptom onset [8-10]. Furthermore, selective expansion of the extracranial arterial system using pituitary adenylate cyclase-activating polypeptide- 38 (PACAP38), correlated strongly with migraine symptoms [11].

Efforts to target the relative imbalance of vasodilation to vasoconstriction of the extracranial vasculature plays a primary role in the treatment of migraine headaches [12-14]. Triptans and ergotamines are widely used abortive medications which do not cross the blood brain barrier, nor effect neuronal transmission. They instead act to target vasoconstrictive effects on the extracranial vasculature $[12,13]$. Transient receptor potential vanilloid subfamily member 1 receptor (TRPV1) selectively dilates the trigeminovascular system and has been shown to reliably induce migraines via vasodilation [15-17].

To date, the best evidence for the extracranial basis of migraines is from indirect inferences, or imaging modalities such as MRA. While these studies lend further proof that the pathophysiology of migraines has an extracranial basis, no study has utilized higher resolution imaging with time-linking in order to test this theory in further detail.

It is conceivable that more detailed vascular imaging could be used to determine whether the extracranial vascular hypothesis of migraine pain is testable and demonstrates a focus for treatment in the future. Digital subtraction angiography remains the gold standard for dynamic vascular imaging, and while techniques have substantially decreased complications in recent years, there are still risks to this procedure which precludes angiography as a means to test the extracranial vascular hypothesis in the general migraine population. Potentially, if there is a way to offset the risks of angiography in patients already undergoing this procedure, who also have migraine headaches, a cohort may be established to determine the role of ECA vessels in migraine pain. A proof of concept study must be performed first to demonstrate the feasibility and safety of DSA to replicate migraine symptoms with specificity for vascular territory and symptomatology, and then therapeutic interventions may be trialed, including either temporary or permanent occlusion of these vessels in order to treat these patients. The possibilities for the future are substantial, and if symptoms are unable to be replicated with super selective manipulation of these vessels, we may once and for all settle this debate between migraine researchers.

\section{References}

1. Hazard E, Munakata J, Bigal ME, Rupnow MF, Lipton RB (2009) The burden of migraine in the United States: current and emerging perspectives on disease management and economic analysis. Value Health 12: 55-64. [Crossref]

2. Starling AJ, Dodick DW (2015) Best practices for patients with chronic migraine: burden, diagnosis, and management in primary care. Mayo Clin Proc 90: 408-414. [Crossref]

3. Turner-Bowker DM, Bayliss MS, Ware JE Jr, Kosinski M (2003) Usefulness of the SF-8 Health Survey for comparing the impact of migraine and other conditions. Qual Life Res 12: 1003-1012. [Crossref]

4. Goadsby PJ, Charbit AR, Andreou AP, Akerman S, Holland PR (2009) Neurobiology of migraine. Neuroscience 161: 327-341. [Crossref]

5. Costa C, Tozzi A, Rainero I, Cupini LM, Calabresi P, et al. (2013) Cortical spreading depression as a target for anti-migraine agents. J Headache Pain 14: 62. [Crossref]

6. Wolff HG, Tunis MM, Goodell H (1953) Studies on headache; evidence of damage and changes in pain sensitivity in subjects with vascular headaches of the migraine type. AMA Arch Intern Med 92: 478-484. [Crossref]

7. Schoonman GG, van der Grond J, Kortmann C, van der Geest RJ, Terwindt GM, et al (2008) Migraine headache is not associated with cerebral or meningeal vasodilatation-a 3T magnetic resonance angiography study. Brain 131: 2192-200. [Crossref]

8. Nagata E, Moriguchi H, Takizawa S, Horie T, Yanagimachi N, et al. (2009) The middle meningeal artery during a migraine attack: $3 \mathrm{~T}$ magnetic resonance angiography study. Intern Med 48: 2133-2135. [Crossref]

${ }^{\star}$ Correspondence to: Rose Fluss, The Albert Einstein College of Medicine, 1300 Morris Park Ave, Bronx, New York 10467, USA, E-mail: fluss@mail.einstein.yu.edu

Key words: migraine, digital subtraction angiography

Received: May 15, 2019; Accepted: May 24, 2019; Published: May 28, 2019 
9. Asghar MS, Hansen AE, Kapijimpanga T, van der Geest RJ, van der Koning P, et al. (2010) Dilation by CGRP of middle meningeal artery and reversal by sumatriptan in normal volunteers. Neurology 75:1520-1526. [Crossref]

10. Amin FM, Asghar MS, Hougaard A, Hansen AE, Larsen VA, et al. (2013) Magnetic resonance angiography of intracranial and extracranial arteries in patients with spontaneous migraine without aura: a cross-sectional study. Lancet Neurol 12: 454461. [Crossref]

11. Amin FM, Hougaard A, Schytz HW, Asghar MS, Lundholm E, et al. (2014) Investigation of the pathophysiological mechanisms of migraine attacks induced by pituitary adenylate cyclase-activating polypeptide-38. Brain 137: 779-94. [Crossref]

12. Shevel E (2009) The trigeminovascular system--quo vadis? Headache 49: 785-786. [Crossref]
13. Shevel E (2011) The extracranial vascular theory of migraine: an artificial controversy. J Neural Transm (Vienna) 118: 525-530. [Crossref]

14. Shevel E (2011) The extracranial vascular theory of migraine--a great story confirmed by the facts. Headache 51: 409-417. [Crossref]

15. Meents JE, Neeb L, Reuter U (2010) TRPV1 in migraine pathophysiology. Trends Mol Med 16: 153-159. [Crossref]

16. Edvinsson L, Linde M (2010) New drugs in migraine treatment and prophylaxis: telcagepant and topiramate. Lancet 376: 645-655. [Crossref]

17. Meents JE, Hoffmann J, Chaplan SR, Neeb L, Schuh-Hofer S, et al. (2015) Two TRPV1 receptor antagonists are effective in two different experimental models of migraine. $J$ Headache Pain 16: 57. [Crossref]

Copyright: (2019 Fluss R. This is an open-access article distributed under the terms of the Creative Commons Attribution License, which permits unrestricted use, distribution, and reproduction in any medium, provided the original author and source are credited. 